\title{
Avaliação hidrodinâmica de unidade piloto de floculação mecanizada
}

\section{Hydrodynamic evaluation of a mechanical flocculation pilot unit}

\author{
Jesus Leonardo Cestari \\ Químico e Mestre em Tecnologia Ambiental pela Faculdade de Engenharia de Ilha Solteira da Universidade Estadual Paulista Júlio de Mesquita Filho (UNESP) - \\ Ilha Solteira (SC), Brasil.

\section{Tsunao Matsumoto} \\ Engenheiro Civil, Mestre e Doutor em Hidráulica e Saneamento pela Escola de Engenharia de São Carlos da Universidade de São Paulo (USP). Livre-docente \\ do Departamento de Engenharia Civil da Faculdade de Engenharia de Ilha Solteira da UNESP - Ilha Solteira (SC), Brasil.
}

\section{Milton Dall'Aglio Sobrinho}

Engenheiro Civil, Mestre e Doutor em Hidráulica e Saneamento pela Escola de Engenharia de São Carlos da USP. Livre-docente do Departamento de Engenharia Civil da Faculdade de Engenharia de Ilha Solteira da UNESP - Ilha Solteira (SC), Brasil.

\section{Marcelo Libânio}

Engenheiro Civil e Mestre em Engenharia Sanitária pela Universidade Federal de Minas Gerais (UFMG). Doutor em Hidráulica e Saneamento pela Escola de Engenharia de São Carlos da USP. Pós-doutorado pela Universidade de Alberta (Canadá). Pesquisador do CNPq. Professor Associado do Departamento de Engenharia Hidráulica e Recursos Hídricos da UFMG - Belo Horizonte (MG), Brasil.

\section{Resumo}

No presente trabalho realizou-se estudo de hidrodinâmica visando avaliar a magnitude do curto-circuito para cinco distintas configurações de aberturas entre as câmaras de uma unidade piloto de floculação mecanizada, para gradientes de velocidade constante e variável, e alternância do sentido da rotação do agitador. O estudo evidenciou que a relevância da configuração das aberturas cresce à medida que o número de câmaras diminui. Em contrapartida, o sentido da rotação dos agitadores e a magnitude do gradiente de velocidade - constante ou variável - apresentaram-se como fatores de menor significância. Tais resultados descortinam alternativa viável de melhoria desta operação unitária, sem investimentos de maior monta, em especial para unidades de floculação de duas ou três câmaras de estações de tratamento de água operando com sobrecarga.

Palavras-chave: floculação mecanizada; avaliação hidrodinâmica; curto-circuito; tratamento de água.

\section{Abstract}

This work focused on the hydrodynamic research aiming at the short-circuiting evaluation for five different outlet configurations through the compartments of a vertical paddle flocculation pilot unit. The tests were carried out with variable and constant velocity gradients, including alternative rotation direction of the paddles. The research pointed out that the relevance of outlet configuration increases with the reduction of the number of compartments. In opposite, the velocity gradient and the rotation direction of paddles seem less significant features. These results open the perspective of viable increasing of performance, with low financial investments, mainly for flocculation units with three or two compartments installed in overloaded water treatment plants.

Keywords: mechanical flocculation unit; hydrodynamic evaluation; short-circuiting; water treatment.

\section{Introdução e relevância}

Levantamento realizado pelo IBGE, abarcando dados de 2008, apontou que as estações dotadas da tecnologia convencional de potabilização - também denominada ciclo completo - faziam-se presentes em 2.817 dos 5.564 municípios do País. Partindo da premissa que há significativo percentual destes municípios com mais de uma unidade de potabilização, torna-se possível estimar como superior a 3.000 o número de estações convencionais de tratamento de água atualmente em operação. Ainda segundo o IBGE, há 290 municípios com população superior a 50 mil habitantes, cuja população no conjunto soma quase 100 milhões de habitantes. A maciça opção por mananciais de superfície para o abastecimento de comunidades de maior porte conduz usualmente a estações de tratamento destinadas a potabilizar vazão média superior a 120-150 L.s ${ }^{-1}$, principalmente nas regiões Sul e Sudeste. Como significativa parcela destas é dotada de unidades de 
floculação mecanizada, é possível estimar que haja de 300 a 400 floculadores mecanizados em funcionamento no País e as ampliações recorrentemente recaem para este tipo de unidade de formação dos flocos.

Além da coagulação propriamente dita, outros fatores haverão de influenciar a formação dos flocos, favorecendo o aumento da duração das carreiras de filtração. Destes, o tempo de detenção - também denominado tempo de residência - e o gradiente de velocidade de floculação adquirem posição de relevo, ainda que para as unidades mecanizadas a geometria das câmaras e dos agitadores (de paletas ou tipo turbina) possam também ser, secundariamente, mencionadas.

No sentido estrito do termo, o tempo de detenção teórico corresponderia à razão entre o volume útil da unidade de floculação e a vazão afluente à mesma. Este parâmetro abarca o tempo necessário à redução do número de partículas desestabilizadas, consequência dos choques promovidos pela energia dissipada na massa líquida. Contudo, na prática o valor teórico somente se verifica para as unidades de floculação hidráulica dotadas de maior número de câmaras (preferencialmente superior a oito). Para as unidades mecanizadas, cujo número de câmaras raramente é superior a quatro, há significativo efeito de curto-circuito (LIBÂNIO, 2010). Nestes casos, parcela substancial da vazão afluente permanece na unidade por tempo inferior ao teórico - e esta redução é tão mais significativa quanto menor o número de câmaras -, para o qual podem ter sido definidas, por meio de ensaios de tratabilidade, as dosagens dos produtos químicos utilizados na coagulação.

Para definição do número de câmaras da unidade de floculação alguns fatores devem ser considerados. Para as unidades mecanizadas avalia-se a relação entre o custo dos equipamentos e a inevitável perspectiva de redução da eficiência devido aos referidos curtos-circuitos. Algumas recomendações apontam para mínimo de três câmaras, enquanto outras reforçam a premissa de que os custos de instalação e manutenção dos equipamentos inviabilizariam unidade de floculação com mais de quatro câmaras (LIBÂNIO, 2010). A NBR 12.216 (ABNT, 1992) corrobora esta assertiva ao recomendar que preferencialmente as unidades de floculação mecanizadas sejam dotadas de pelo menos três câmaras. No País, são raras as estações de tratamento dotadas de floculadores mecanizados com mais de quatro câmaras.

Os efeitos de curto-circuito são subjacentemente contemplados nas recomendações da NBR 12.216 (ABNT, 1992) ao aludirem, na ausência de ensaios de tratabilidade, a tempos de floculação de 20 a 30 min para unidades hidráulicas e 30 a 40 min para unidades mecanizadas. Em relação à configuração das aberturas, a mesma norma faz vaga menção no sentido evitar a passagem direta do fluxo através das câmaras e, especificamente, à disposição das passagens.

Alternativa fundada mais no empirismo que em experimentação preconiza a alternância no sentido da rotação das paletas, ou seja, na primeira câmara o eixo gira no sentido horário, na segunda no sentido anti-horário e assim sucessivamente. Todavia, ensaio em unidade piloto de floculação evidenciou a irrelevância desta prática para gradiente de velocidade de floculação constante ao longo das câmaras de $10 \mathrm{~s}^{-1}$ (LIBÂNIO, 2010). A avaliação da eficácia desta alternativa para valores mais elevados de gradiente de velocidade acabou por ser também contemplada na pesquisa.

\section{Objetivos}

Diante do exposto, o objetivo geral do trabalho consistiu em realizar avaliação hidrodinâmica de unidade piloto de floculação mecanizada com câmaras em série e escoamento contínuo, a partir da técnica de estímulo e resposta, visando estimar a magnitude do curto-circuito. Os objetivos secundários foram avaliar a influência: do tipo e das disposições das aberturas entre as câmaras; da magnitude e da gradação, ao longo das câmaras, do gradiente médio de velocidade de floculação; e do sentido da rotação do agitador.

\section{Revisão da literatura}

\section{Modelos de escoamento}

As unidades de floculação constituem-se, na realidade, reatores de escoamento contínuo nos quais os coagulantes são adicionados na unidade de mistura rápida e os flocos retirados na unidade de decantação/ flotação/filtração. No floculador, os flocos são formados para posterior remoção da fase líquida. Os reatores podem apresentar dois tipos de modelos de escoamento ideal, pistão (plug flow) e mistura completa ou mistura perfeita (perfect mixing) (LEVENSPIEL, 2000). As unidades de modelo de escoamento ideal do tipo pistão caracterizam-se por apresentar escoamento ordenado dos elementos do fluido, para o qual todas as moléculas de fluido possuem a mesma velocidade, levando, assim, o mesmo tempo para percorrer o reator, não havendo mistura. Por outro lado, o modelo de escoamento ideal do tipo mistura completa caracteriza-se pela homogeneidade de qualquer propriedade do fluido, em qualquer ponto no interior da unidade e a qualquer tempo, não existindo variações espaciais de propriedades como, por exemplo, concentração e temperatura.

$\mathrm{Na}$ prática, os reatores não seguem exatamente os modelos de escoamento ideal descritos anteriormente e apresentam escoamento arbitrário, ou seja, com maior ou menor desvio aproximam-se mais de um ou de outro (LEVENSPIEL, 2000). O desvio do escoamento ideal pode ser causado pela presença de curtos-circuitos, zonas mortas e recirculação do fluido, assim definidos:

i) curtos-circuitos constituem-se os caminhos preferenciais percorridos pelas moléculas de fluido que resultam, conforme mencionado, em tempos de detenção médios $\left(t_{\mathrm{m}}\right)$ inferiores ao tempo de detenção teórico $(T)$;

ii) zonas mortas apresentam-se em regiões do reator onde os tempos de detenção médios das moléculas de fluido no seu interior são, em média, relativamente altos, quando comparados ao valor de $T$. Como consequência, verificam-se nestas regiões baixa 
troca de massa e pequena quantidade de movimento com regiões adjacentes;

iii) recirculação do fluido traduz o retorno das moléculas do fluido para o interior do reator

\section{Tempo real de floculação e tempo de detenção teórico}

Embora a magnitude do curto-circuito relacione-se, além do número de câmaras, com o tamanho e disposição das aberturas - conferindo certa individualidade a cada unidade de floculação -, modelos matemáticos apresentam-se como razoável estimativa do tempo real de floculação. Ainda na década de 1950, Camp (1955) apresentou o modelo fundamentado na Equação 1.

$\frac{C}{C_{0}}=\frac{n^{n}}{(n-1) !}\left(\frac{T_{f}}{T}\right)^{n-1} e^{-n T_{f} / T}$

Na qual:

n: número de câmaras em série da unidade de floculação;

Co, C: concentração do traçador na entrada e na saída da unidade, respectivamente (mg. $\left.\mathrm{L}^{-1}\right)$;

Tf: tempo real de floculação (min);

T: tempo teórico de detenção da unidade de floculação (min).

Pelo emprego da Equação 1, considerando unidade de floculação de três câmaras, constata-se que aproximadamente 4\% do volume do traçador deixam a unidade de floculação em um quarto do tempo de detenção teórico e 19\% na metade deste tempo.

Com mesmo intento, modelo ainda mais simples foi proposto por Bratby (1981), apresentado na Equação 2, envolvendo os mesmos parâmetros da Equação 1.

$$
\mathrm{T}=\mathrm{T}_{\mathrm{f}} \frac{\mathrm{n}}{\mathrm{n}-1}
$$

De acordo com a Equação 2, para uma unidade de floculação com três câmaras em série, o tempo de detenção real seria aproximadamente 66\% do teórico. Em outras palavras, o tempo teórico deve-se ser elevado em 50\% para se igualar ao tempo de floculação adotado nos ensaios de tratabilidade em reatores estáticos. Nesta premissa, para uma unidade de floculação hidráulica dotada de 10 câmaras, o tempo real torna-se $90 \%$ do teórico, comprovando o ínfimo efeito de curto-circuito.

\section{Aplicação e características dos traçadores}

Os efeitos de curtos-circuitos em unidades de floculação mecanizada podem ser avaliados por meio de ensaios de traçador, com uso da técnica de estímulo e resposta, que consiste na adição de traçador na entrada da unidade, medindo-se sua concentração na saída. Desta forma, o conhecimento das características hidráulicas das unidades de floculação constitui-se importante ferramenta na realização dos ensaios de tratabilidade, especialmente em reatores estáticos, que podem ser executados de acordo com as características da unidade avaliada (DI BERNARDO; DANTAS, 2005).

O conhecimento da distribuição do tempo de residência de elementos de fluido é utilizado para caracterizar o grau de não idealidade do escoamento. Conforme salientado, esta informação pode ser facilmente determinada pela técnica de estímulo e resposta. Segundo Levenspiel (2000), a técnica de estímulo e resposta consiste em verificar a resposta do sistema a um estímulo qualquer. Qualquer sinal de entrada de traçador pode ser usado como estímulo, destacando-se pulso, degrau, casual ou periódico. Nesta pesquisa, considerou-se apenas a função pulso, por ser de mais simples aplicabilidade e atender de forma plenamente satisfatória aos objetivos delineados.

Alguns fatores são determinantes na escolha do traçador como a vazão afluente à estação, as dimensões das unidades, a qualidade da água e o custo do produto. Podem ser empregados corantes (fluoresceína, rodamina), sais (fluoreto de sódio, fluoreto de potássio, cloreto de cálcio, cloreto de sódio, hipoclorito de sódio) e bases (hidróxido de sódio). Precedendo a escolha do traçador, deve-se assegurar que (DI BERNARDO; DANTAS, 2005):

i) sua concentração na água seja consistentemente baixa e aproximadamente constante;

ii) não reaja com compostos presentes na água;

iii) seja facilmente detectado e medido na água.

\section{Distribuição dos tempos de residência}

De acordo com Levenspiel (2000), os elementos de fluido que adotam caminhos diferentes através do reator percorrem em tempos diferentes todo o recipiente. Assim, a distribuição destes tempos para a corrente de fluido deixando o reator denomina-se distribuição de idade de saída, E (do inglês exit), ou distribuição do tempo de residência (detenção) do fluido (DTR). É conveniente representar a DTR de modo que a área sob a curva seja igual à unidade (distribuição na forma normalizada), conforme descrita pela Equação 3.

$\int_{0}^{\infty} E d t=1$

A fração da corrente de saída com idade (tempo despendido por aquele elemento de fluido no recipiente) entre $t$ e $t+d t$ é igual a $E d t$, enquanto a fração mais nova que a idade $t_{1}$ é representada pela Equação 4.

$\int_{0}^{t 1} E d t=1$

Enquanto que a fração de fluido mais antiga que $t_{1}$ é apresentada pela Equação 5.

$\int_{\mathrm{tl}}^{\infty} E d t=1-\int_{0}^{\mathrm{t} 1} E d t$ 
A Curva E ou DTR é a distribuição necessária na avaliação do grau de desvio da idealidade do escoamento. Na Figura 1, apresenta-se a curva DTR normalizada, destacando na área sombreada a fração de fluido que permanece no reator por tempo superior a $t_{1}$.

\section{Determinação experimental da Curva E}

A maneira mais simples e direta de determinar a Curva E consiste no emprego de traçador físico e não reativo no reator que se deseja avaliar. Segundo Levenspiel (2000), para encontrar a Curva E para recipiente com volume $V$, através do qual um fluido escoa com vazão $Q$, basta introduzir instantaneamente, no afluente, $M$ unidades do traçador e registrar a concentração e o tempo do traçador ao deixar o recipiente. Desta forma, a partir da obtenção da curva concentração vs. tempo, pode ser realizado o cálculo da área (A) abaixo da curva, conforme mostra a Equação 6.

$$
A=\int_{0}^{\infty} C d t \cong \sum_{i} c_{i} \cdot \Delta t i=\frac{M}{Q}
$$

Na qual:

$\mathrm{c}_{\mathrm{i}}$ : Concentração de traçador no tempo i;

$\Delta \mathrm{t}_{\mathrm{i}}$ : Intervalo de tempo.

O tempo de residência médio $\left(\mathrm{t}_{\mathrm{m}}\right)$ pode ser determinado empregando-se a Equação 7.

$t_{m}=\frac{\int_{0}^{\infty} t C d t}{\int_{0}^{\infty} C d t}=\frac{\sum_{i} t_{i} c_{i} \Delta t_{i}}{\sum_{i} c_{i} \Delta t_{i}}=\frac{V}{Q}$

Para encontrar a Curva E a partir da curva concentração pelo tempo, basta simplesmente mudar a escala de concentração, de modo que a área sob a curva seja igual à unidade. Assim, simplesmente dividem-se as leituras de concentração por $M / Q$, como mostrado na Equação 8.

$E_{i}=\frac{c_{i}}{M / Q} \cong \frac{c_{i}}{\sum_{i} c_{i} \cdot \Delta t_{i}}$

$\mathrm{Na}$ qual:

$E_{\mathrm{i}:}$ : Distribuição de idade de saída no tempo i.

Outra forma de visualização da curva DTR provém da conversão da Curva $E$ para a função $E_{\theta}$, que adimensionaliza a escala de tempo, ao empregar o parâmetro $\theta=t / t_{\mathrm{m}}$. Este artifício traz indubitável vantagem de permitir comparação da perspectiva de ocorrência de curtos-circuitos entre distintas unidades de floculação, prescindindo da magnitude do tempo de detenção teórico. Em outras palavras, o emprego destes parâmetros torna desimportante o conhecimento das dimensões da unidade de floculação e da vazão afluente. Assim, a nova função é obtida como mostrado na Equação 9 e exemplificada na Figura 2.

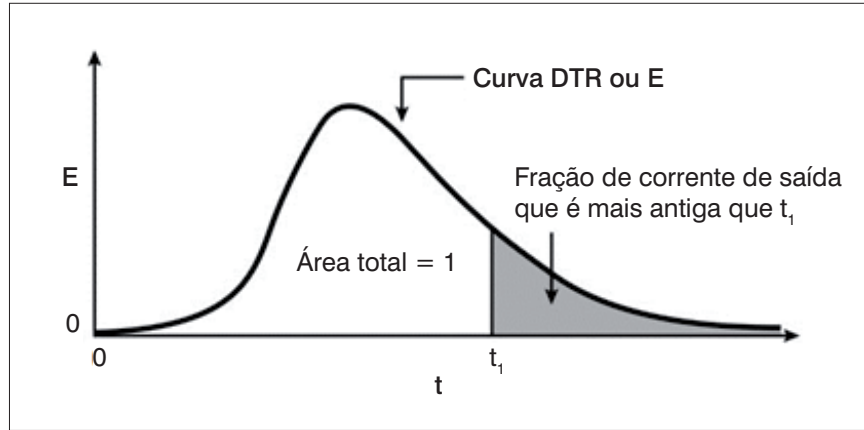

Figura 1 - Curva de distribuição do tempo de residência curva $E$ (LEVENSPIEL, 2000).

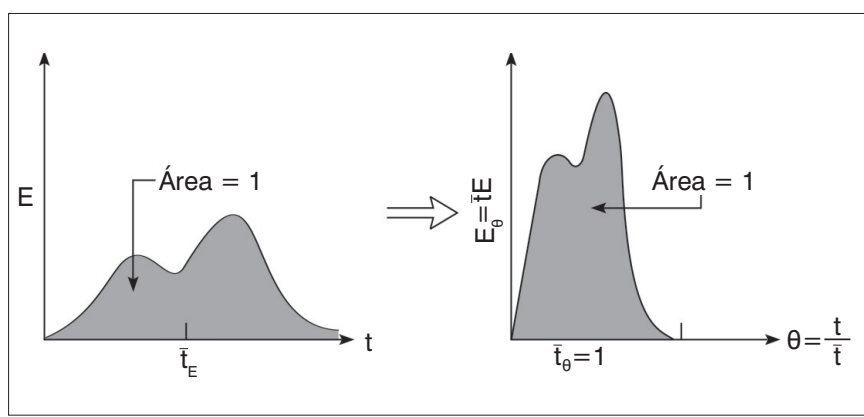

Figura 2 - Transformação da curva $\mathrm{E}_{\text {em }} \mathrm{E}_{\theta}$ (LEVENSPIEL, 2000).

$E_{\theta}=t_{m} \cdot E_{i}=\frac{V}{Q} \cdot \frac{c_{i}}{M / Q}=\frac{V}{M} \cdot c_{i}$

Segundo Rebhun e Argaman (1965), tm constitui parâmetro adequado para caracterizar a eficiência das unidades de floculação. Segundo os autores, quando este parâmetro iguala-se ao tempo de residência teórico, não há problemas de escoamento com o reator. Porém para tm menores que T há formação de zonas mortas e consequentemente manifestam-se os curtos-circuitos hidráulicos.

\section{Modelo de escoamento não ideal}

De acordo com Levenspiel (2000), os modelos matemáticos são úteis para representar escoamentos em reatores, possibilitando comparar as curvas obtidas experimentalmente às do modelo de escoamento ideal. Em floculadores nos quais curtos-circuitos, zonas mortas ou recirculação do fluido se manifestam as curvas DTR experimentais caracterizam-se por apresentarem, respectivamente, picos antecipados em relação ao tempo de residência teórico, longas caudas e oscilações na curva. Para o presente trabalho, o modelo de tanques em série foi escolhido por representar o escoamento em mistura nos floculadores mecanizados.

No modelo de tanques em série, estabelece-se o número $(N)$ de unidades de mesmo volume, igualmente agitados, através das quais o fluido escoa. O grau de mistura caracteriza-se pelo número de tanques. Desta forma, quanto maior o número de tanques - o que equivale ao número de câmaras do floculador - mais baixo é o grau de mistura e, no caso limite de um número infinito 
de tanques, prevalece o escoamento pistonado. $\mathrm{O}$ delineamento das curvas ideais para este modelo é descrito pela Equação 10 (LEVENSPIEL, 2000) e ilustrado pela Figura 3.

$$
E_{\theta}=N \frac{(N \theta)^{N-1}}{(N-1)} e^{-N \theta}
$$

$\mathrm{Na}$ qual:

$\mathrm{N}$ : número de tanques;

$\theta$ : tempo de residência (adimensional).

\section{Metodologia}

\section{Aparato experimental}

Unidade de floculação mecanizada de escoamento contínuo foi construída em acrílico transparente de $10 \mathrm{~mm}$ de espessura, com quatro câmaras em série de volume útil de 144 L cada uma, de seção quadrada de $60 \mathrm{~cm}$ e altura útil de $40 \mathrm{~cm}$, com passagens quadradas de $10 \mathrm{~cm}$ de lado. Compartimentos de $36 \mathrm{~L}$ foram instalados na entrada e na saída do floculador para auxiliarem no funcionamento do aparato quando operando com vazão constante.

No equipamento de agitação empregaram-se paletas paralelas ao eixo vertical, dimensionado de acordo com as recomendações de Di Bernardo e Dantas (2005). Desta forma, tal equipamento foi projetado com quatro braços e duas paletas por braço. As paletas apresentavam dimensões de $35 \times 2,5 \mathrm{~cm}$, distantes $2,5 \mathrm{~cm}$ tanto da superfície quanto do fundo. A distância do centro do eixo ao centro das paletas foi de 18,75 e 23,75 cm. A rotação foi calculada considerando o coeficiente $\mathrm{K}_{\mathrm{ap}}$ variável em função da posição das paletas, conforme recomendação de Campos (1992), para obter o gradiente de velocidade médio desejado.

Para promover a agitação, foram empregados motores do tipo moto-redutor, sendo uma unidade para cada agitador. A mudança do sentido da rotação do agitador foi realizada invertendo-se os polos positivo e negativo na fonte de alimentação.

Segundo Camp (1955), a potência dissipada pelo agitador na água correspondente a um braço e duas paletas por braço $\left(\mathrm{P}_{1 \mathrm{b2}}\right)$ pode ser estimada por meio da Equação 11:

$$
P_{1 b 2}=5,85 \cdot 10^{-5} \gamma C_{d}\left[\left(1-K_{a p}\right) N_{l}\right]^{3} A_{p} R_{p}^{3}
$$

$\mathrm{Na}$ qual:

$\gamma$ : peso específico da água $\left(\mathrm{N} . \mathrm{m}^{-3}\right)$;

$C_{d}$ : coeficiente de arrasto (função da razão entre comprimento e largura da paleta);

$\mathrm{K}_{\mathrm{ap}}$ : relação entre a velocidade da paleta e da água no interior da câmara;

$\mathrm{N}_{\mathrm{r}}$ : número de rotações (rpm);

$\mathrm{A}_{\mathrm{p}}$ : área da paleta $\left(\mathrm{m}^{2}\right)$.

$\mathrm{R}_{\mathrm{p}}$ :distância do centro do eixo do agitador ao centro da paleta (m).

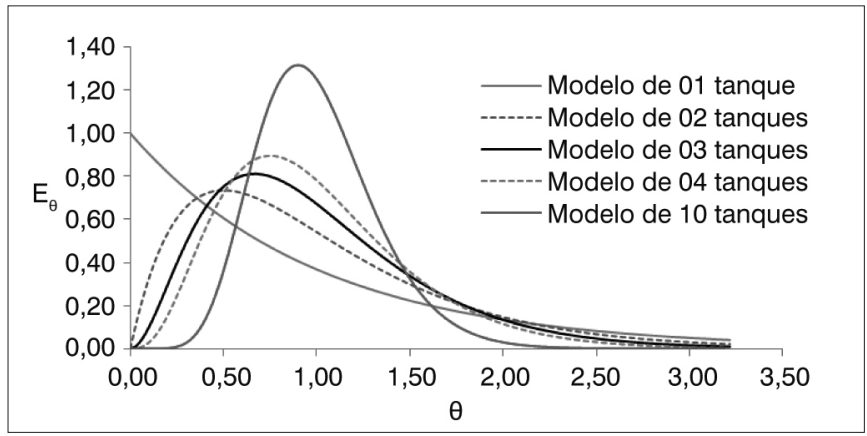

Figura 3 - Curvas de DTR para modelos de tanques em série (adaptado de LEVENSPIEL, 2000).

Vale salientar que, na presente pesquisa, adotou-se como $\mathrm{K}_{\text {ap }}$ o valor de 0,15 para a paleta mais próxima ao eixo e 0,20 para a mais distante e $C_{d}$ igual a 1,345 para a relação comprimento e altura igual a 14. Após determinar a potência correspondente a um braço e duas paletas $\left(\mathrm{P}_{1 \mathrm{~b} 2}\right)$, calculou-se a potência dissipada pelo agitador multiplicando $\mathrm{P}_{1 \mathrm{~b} 2}$ pela potência máxima $\left(\mathrm{P}_{\max }\right)$ e mínima $\left(\mathrm{P}_{\min }\right)$ para o agitador com quatro braços e duas paletas por braço $\left(\mathrm{P}_{4 \mathrm{~b} 2}\right)$, conforme determinadas experimentalmente por Campos (1992).

Desta forma, para o cálculo da potência introduzida na câmara de floculação que resultasse o gradiente de velocidade médio de floculação desejado, empregou-se a Equação 12:

$$
G_{f}=\sqrt{\frac{P_{f}}{\mu V_{c}}}
$$

Na qual:

Gf: gradiente de velocidade médio de floculação $\left(\mathrm{s}^{-1}\right)$;

$\mathrm{P}_{\mathrm{f}}$ : potência dissipada pelo agitador em uma câmara de floculação (W);

$\mathrm{V}_{\mathrm{c}}$ : volume da câmara $\left(\mathrm{m}^{3}\right)$;

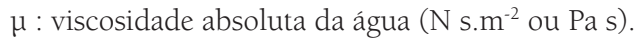

Por fim, para obtenção das rotações do equipamento de agitação que resultassem no gradiente de velocidade médio desejado, empregaram-se as equações 13 e 14 (DI BERNARDO; DANTAS, 2005):

$$
N r_{\text {max }}=\left(\frac{P_{f}}{P_{\text {min }}}\right)^{1 / a}
$$

$$
N r_{\text {min }}=\left(\frac{P_{f}}{P_{\max }}\right)^{1 / a}
$$

Sendo:

$\mathrm{N}_{\mathrm{r} \max }$ e $\mathrm{N}_{\mathrm{r} \text { min }}$ : número de rotações máximas e mínimas, respectivamente, do equipamento de agitação (rpm).

A comunicação entre as câmaras deu-se por meio de aberturas quadradas de $10 \mathrm{~cm}$ de lado. Para a estimativa de Gf nas passagens 
considerou-se a vazão máxima, empregando-se a Equação 15 (DI BERNARDO; DANTAS, 2005):

$$
G_{f}=\left(\frac{\gamma}{2 \mu g}\right)^{1 / 2}\left(\frac{f}{4 R_{h}}\right)^{1 / 2}(V p)^{a / 2}
$$

Na qual:

g: aceleração da gravidade $\left(\mathrm{m} / \mathrm{s}^{2}\right)$;

f : coeficiente de perda de carga da Equação Universal (função da rugosidade da abertura);

$\mathrm{R}_{\mathrm{h}}$ raio hidráulico $(\mathrm{m})$;

$\mathrm{V}_{\mathrm{p}}$ :velocidade média de escoamento através das passagens $\left(\mathrm{m} . \mathrm{s}^{-1}\right)$.

Como as aberturas tinham as mesmas dimensões, o gradiente de velocidade das passagens foi o mesmo, da ordem de $3 \mathrm{~s}^{-1}$, e significativamente inferior ao da câmara anterior.

Na Figura 4 apresenta-se desenho esquemático do aparato experimental utilizado nos ensaios de avaliação hidrodinâmica.

A alimentação efetuava-se por meio reservatório de nível constante e a vazão era regulada por registro. A retirada da água realizavase por vertedor do tipo tulipa, instalado na caixa de saída em local distante da abertura da última câmara. Tubulações em PVC, cotovelos, tês, registros e bomba foram empregados para compor o circuito hidráulico da unidade em estudo. A injeção do traçador realizava-se através de dispositivo composto por reservatório, suportes de apoio, mangueiras e válvula.

\section{Configuração das aberturas entre as câmaras}

Para a realização do estudo da hidrodinâmica no floculador de quatro, três e duas câmaras, o principal parâmetro de avaliação foi a combinação de diferentes configurações de passagem ao sentido da rotação do agitador e à magnitude do gradiente de velocidade (constante e variável). Entre as câmaras havia quatro diferentes posições de passagem que interligava uma câmara a outra. Para tanto, fechavam-se três posições (com plástico acrílico e silicone) e mantinha-se apenas uma passagem aberta. Como a principal função das aberturas em floculadores mecanizados é apenas realizar a passagem da água de uma câmara a outra, procurou-se avaliar as diferentes configurações de passagem por meio da curva DTR.

Para melhor compreensão dos desenhos definiram-se as cinco configurações das passagens por letras maiúsculas (superiores) e minúsculas (inferiores), adotando-se o sentido do escoamento de entrada da água como parâmetro inicial. Na Figura 5, exemplificam-se quatro das configurações de passagens para o floculador de quatro câmaras (eeeee, edede, eDeDe e eEeEe). Omitem-se os agitadores para facilitar o entendimento dos desenhos.

Conforme salientado, em uma quinta configuração avaliouse a DTR empregando-se anteparos quadrados de $10 \mathrm{~cm}$ de lado (recebendo o código e/e/e/e/e para unidade com quatro câmaras), defronte às passagens distantes $10 \mathrm{~cm}$ das mesmas (Figura 6). O objetivo do anteparo foi impelir o escoamento na direção ascendente, similar ao funcionamento dos floculadores hidráulicos de escoamento helicoidal.

As configurações de passagem estudadas para o floculador de quatro câmaras foram também estudadas para três e duas câmaras. Para tal, alterou-se o ponto de análise da condutividade elétrica do efluente da saída da quarta câmara, para a saída da terceira e segunda câmaras.

\section{Ensaios experimentais}

A avaliação hidrodinâmica deu-se por meio de determinações de condutividade elétrica a partir de condutivímetro Digimed, modelo DM 3, acoplado a um microcomputador. A cada ensaio

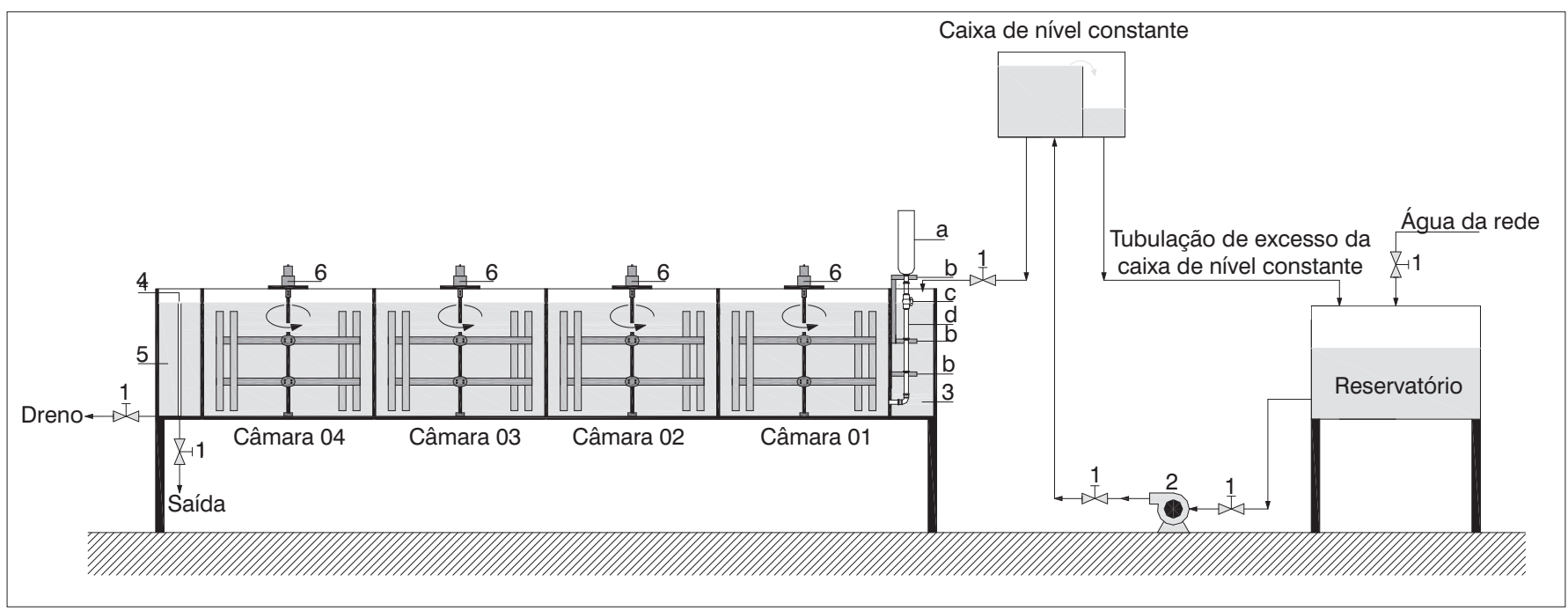

Figura 4 - Desenho esquemático do aparato experimental. Instalação experimental: (1) registro; (2) bomba; (3) caixa de entrada; (4) vertedor; (5) caixa de saída; (6) moto-redutor. Dispositivo de lançamento do traçador: (a) reservatório; (b) suporte de apoio; (c) válvula; (d) mangueira de ligação. 
CAIXA DE ENTRADA

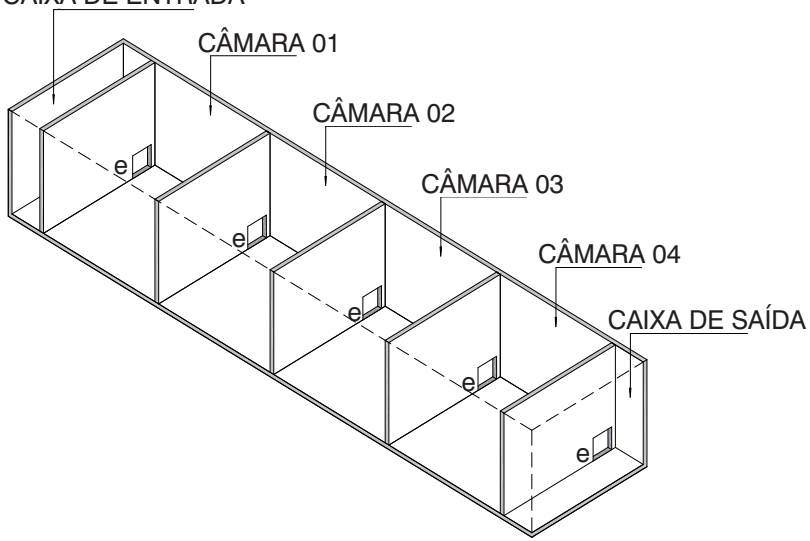

CAIXA DE ENTRADA

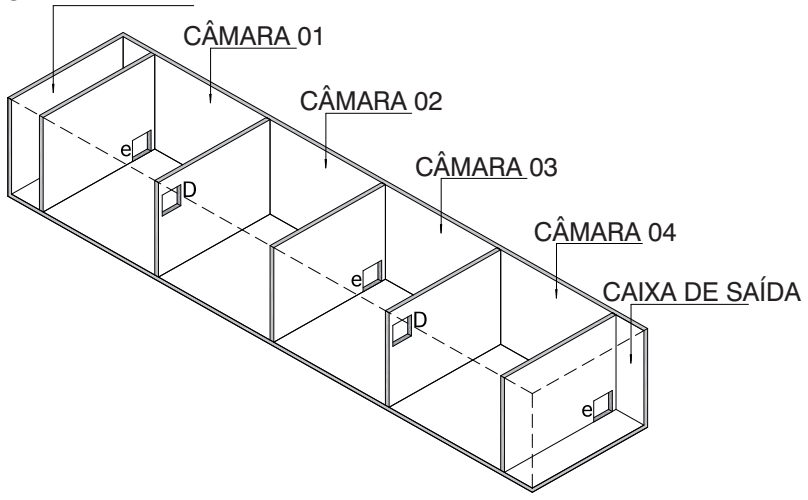

\section{CAIXA DE ENTRADA}

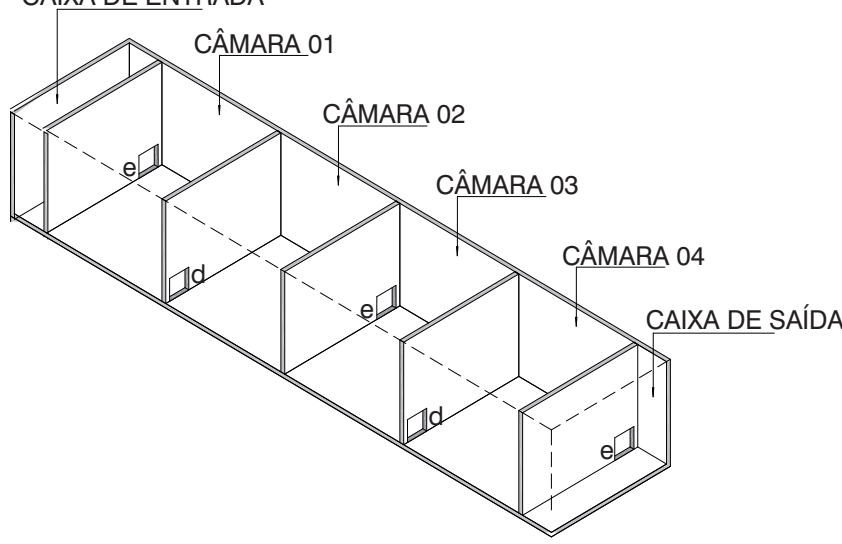

CAIXA DE ENTRADA

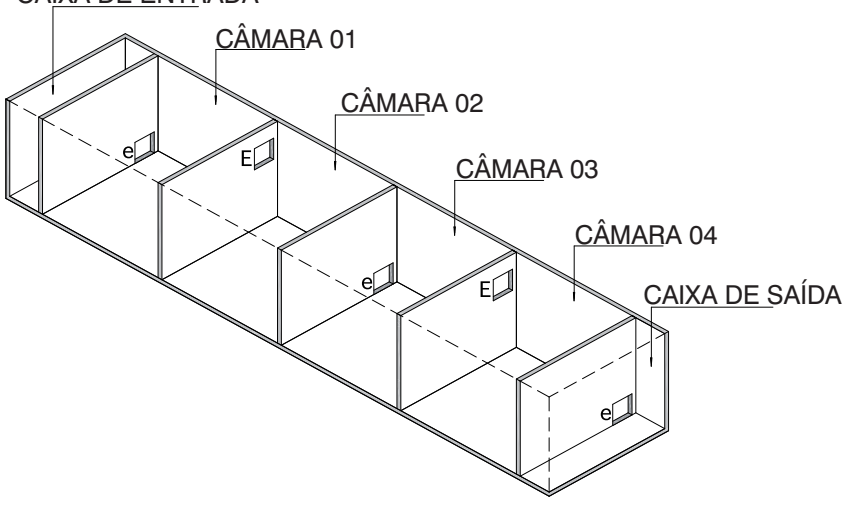

Figura 5 - Configurações de aberturas para unidade de floculação com quatro câmaras.

utilizou-se volume de $250 \mathrm{~mL}$ de solução de traçador preparada em laboratório, composta por 25 g de cloreto de sódio ( $\mathrm{NaCl} \mathrm{P.A.),}$ $137,5 \mathrm{~mL}$ de etanol (álcool etílico) e água destilada. A adição do etanol se fez necessária para regulagem da densidade da solução salina, reduzida até se aproximar da densidade da água em estudo, evitando a estratificação do escoamento e acúmulo de traçador no fundo da unidade de floculação, de acordo com recomendações de Hudson (1975).

O procedimento utilizado foi o mesmo para todos os ensaios, fazendo-se uso da técnica de estímulo e resposta. Procedeu-se à alimentação prévia dos floculadores, antes da injeção do traçador, até que o sistema entrasse em regime permanente.

Para injeção do volume de traçador, construiu-se dispositivo de injeção por gravidade, que dispersava a solução no ponto central da passagem esquerda inferior que dá acesso à primeira câmara da unidade piloto, sendo esta passagem adotada para todos os demais ensaios. Estabeleceu-se tempo de injeção da ordem de $25 \mathrm{~s}$ para todos os ensaios, para que o mesmo fosse inferior a 3\% do tempo teórico e considerado do tipo pulso (DI BERNARDO; DANTAS, 2005).

O dispositivo de lançamento do traçador era escorvado antes do seu uso para minimizar os efeitos das bolhas de ar na tubulação.

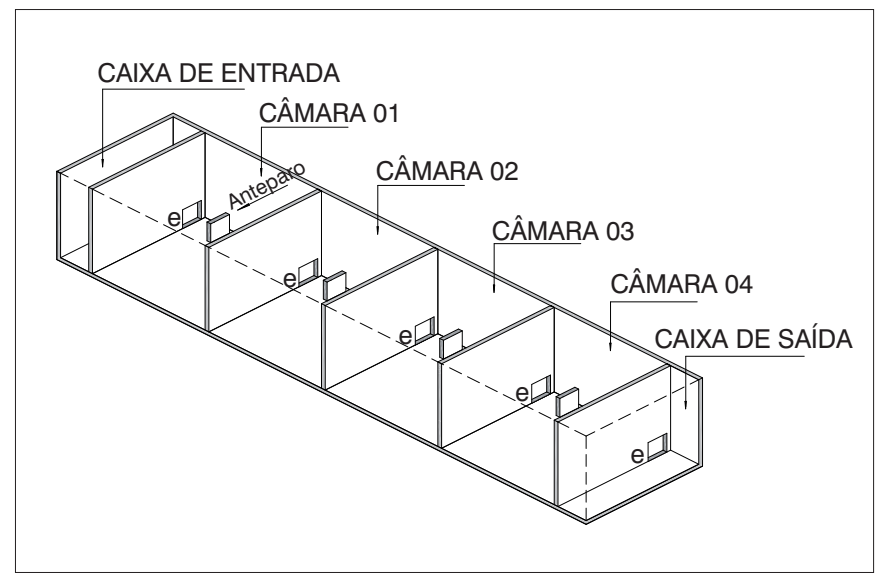

Figura 6 - Configuração das passagens com anteparo.

Este procedimento consistia no lançamento de água no reservatório e fechamento da válvula de modo que a água armazenada na mangueira não apresentasse bolhas. Em seguida, o volume de traçador era colocado no reservatório e a válvula aberta para o lançamento. Após a abertura da válvula e a dispersão total do traçador, volume de aproximadamente $50 \mathrm{~mL}$ de água destilada era lançado para evitar a perda de material no dispositivo. 
Imediatamente após a injeção do traçador, iniciavam-se as leituras da condutividade elétrica no efluente da unidade de floculação por meio de sonda, não sendo necessária a coleta de amostras. As leituras realizaramse em intervalos regulares de tempo de um minuto, prolongando-se por até três vezes o tempo teórico de residência, conforme recomendação de Teefy (1996). As medições foram sempre realizadas na saída da unidade estudada. Desta forma, quando estudado o floculador com duas câmaras, as análises foram realizadas na saída da segunda câmara. De forma semelhante, realizaram-se os estudos com três e quatro câmaras.

As medidas da concentração do $\mathrm{NaCl}$ P.A. foram realizadas por meio de análise condutimétrica, que relaciona a condutividade total da solução à sua concentração. As análises foram realizadas por meio de célula de condutividade, não sendo necessária a coleta de amostras. Prepararam-se soluções de concentrações conhecidas, a partir das soluções-mãe, e medidas as condutividades, obtendo-se as equações de correlação entre os dois parâmetros.

A vazão era aferida volumetricamente, antes e após a realização de cada ensaio, na saída da unidade de floculação. A vazão média foi mantida em 19,5 L. $\mathrm{min}^{-1}$ para todos os ensaios, resultando três tempos de residência médios de: 29,5; 22,2; e 14,8 min, respectivamente, para os floculadores de quatro, três e duas câmaras. Nestas circunstâncias, as velocidades através das passagens eram da ordem de $3,3 \mathrm{~cm} . \mathrm{s}^{-1}$ resultando, conforme mencionado, em gradientes de velocidade nas passagens inferiores a $3 \mathrm{~s}^{-1}$. Desta forma, o tempo de residência teórico $(\mathrm{T})$ empregado para os floculadores, inferior ao tempo mínimo recomendado pela NBR 12.216 (ABNT, 1992) - 30 min para unidades mecanizadas, conforme salientado não interferiu nos objetivos do trabalho, pois o mesmo não contemplou avaliação de eficiência de floculação.

\section{Gradiente de velocidade e sentido da rotação dos agitadores}

Para cada uma das cinco configurações, avaliou-se a influência do sentido da rotação dos agitadores e da variabilidade e da constância dos gradientes de velocidade médios de floculação (Gf). Para tal, a partir das recomendações da NBR 12.216 (ABNT, 1992) que estabelecem intervalo de 10 e $70 \mathrm{~s}^{-1}$, definiram-se 5 cenários para estudo:

i) agitadores operando no mesmo sentido de rotação (estudo 1), ou seja, todos no sentido anti-horário, e Gf variável (para quatro câmaras definiu-se sequência de 62, 44, 34 e 18 s-1, para três câmaras de 44, 34 e 18 s-1, e para duas câmaras 34 e 18 s-1);

ii) agitadores operando em sentidos alternados de rotação (estudo 2), ou seja, anti-horário e horário, e Gf variável;

iii) agitadores operando no mesmo sentido de rotação e $G f$ constante de $34 \mathrm{~s}^{-1}$ (estudo 3);

iv) Agitadores operando em sentidos alternados de rotação e $G f$ constante de $34 \mathrm{~s}^{-1}$ (estudo 4);

v) Agitadores desligados.
A atipicidade do último cenário avaliado justifica-se, quer pela floculação incidental que conduz à paralisação parcial ou total dos agitadores, quer pela avaria dos motores e ausência de manutenção, principalmente nas estações de tratamento distantes dos centros mais desenvolvidos.

Procurou-se realizar a agitação, sempre que possível, no sentido contrário ao fluxo de entrada de água na câmara, para promover maior mistura e diminuir a probabilidade de se criar caminhos preferenciais. Ao avaliar a DTR para os floculadores de quatro, três e duas câmaras, para os cinco cenários e cada uma das cinco configurações de passagem, realizaram-se 25 ensaios para cada floculador, totalizando 75 ensaios.

\section{Análise estatística dos dados experimentais}

A análise dos dados foi realizada a partir da metodologia proposta por Levenspiel (2000). As curvas experimentais de concentração (c) por tempo (t) foram normalizadas (área sob a curva igual a 1,0), obtendo-se as curvas de distribuição dos tempos de residência adimensional $\left(E_{\theta}\right)$ em função do tempo adimensional $(\theta)$.

As curvas obtidas experimentalmente foram comparadas às curvas ideais, de acordo com o tipo de floculador estudado. Para representar o escoamento nos floculadores de quatro, três e duas câmaras, construíram-se curvas ideais utilizando o modelo de tanques em série, compatibilizando-o ao número de câmaras de cada floculador. Desta forma, inserindo-se o número de tanques em função do tempo adimensional, foi possível criar curvas que representassem fidedignamente o escoamento desejado.

A soma dos erros quadráticos (SEQ) foi determinada a partir da comparação entre a curva experimental e a ideal do modelo de tanques em série, por meio da Equação 16 (AMIRTHARAJAH et al., 1991).

$$
S E Q=\sum\left(E_{\theta(\text { curva do modelo })}-E_{\theta(\text { curva experimental })}\right)^{2}
$$

Na qual:

$\mathrm{E}_{\theta}$ : Distribuição de idade de saída (adimensional).

A análise estatística dos desvios das curvas experimentais em relação à curva ideal do modelo de tanques em série utilizou a comparação entre as médias da SEQ, por meio de testes de significância da diferença entre médias.

O intervalo de confiança utilizado para rejeição da hipótese nula foi de $95 \%$. Entretanto, em amostras pequenas, o desvio padrão da amostra não é uma boa estimativa do desvio padrão da população. Por isso, foi empregada distribuição $t$ de Student, utilizada nos casos em que não é possível retirar grande número de amostras, para determinar o intervalo de confiança das médias amostrais. No teste de hipóteses para a diferença entre médias, estas foram agrupadas duas a duas, e testadas conforme o procedimento usual do teste $t$ para 
diferenças entre duas médias com números de amostras diferentes (STEEL; TORRIE, 1960). O teste F de Fischer também foi aplicado como informação adicional. Os testes foram realizados com todos os dados, sem a eliminação dos valores extremos.

\section{Resultados e discussão}

\section{Ausência de agitação}

Inicialmente, vale ressaltar que em todos os ensaios a porcentagem de traçador recuperado ficou entre 85 e 95\% indicando, segundo Teefy (1996), taxas de recuperação entre bom e ótimo.

A primeira avaliação contemplou as comparações entre as cinco configurações para a atípica situação dos agitadores desligados. $\mathrm{Na}$ Figura 7, apresentam-se tais resultados para a unidade de floculação com quatro e três câmaras. Vale novamente salientar que as curvas DTR denotam no eixo das ordenadas o parâmetro $E_{\theta}$ - distribuição de idade de saída adimensional - e nas abscissas, o parâmetro $\theta$ que representa o tempo adimensional.

$\mathrm{Na}$ ausência de agitação, das curvas DTR depreende-se o quão imprópria é a configuração que alinha as aberturas (eeeee), com o pico manifestando-se em menos de $10 \%$ de $\theta$. Embora não apresentados, os ensaios com a unidade de duas câmaras evidenciou ainda mais significativamente tal característica desta configuração. Em contrapartida, estes ensaios também mostraram nítida supremacia da configuração com anteparos (e/e/e/e/e) sobre as demais. Tais resultados descortinam a possibilidade de inserção dos anteparos nas unidades de floculação cujos agitadores encontram-se avariados ou em manutenção, como forma de favorecer melhor formação dos flocos.

\section{Gradiente de velocidade e sentido da rotação}

Conforme aludido na Metodologia, na etapa subsequente avaliou-se se a magnitude do gradiente de velocidade, constante e variável, e o sentido da rotação dos agitadores influenciam na ordem de grandeza dos curtos-circuitos. Na Figura 8, apresentam-se tais resultados para unidade de floculação de quatro câmaras e duas das cinco configurações de aberturas avaliadas.

Similarmente às curvas DTR mostradas na Figura 8 , as demais configurações evidenciaram a irrelevância destes parâmetros na magnitude do curto-circuito quando a unidade de floculação é dotada de quatro câmaras.
A

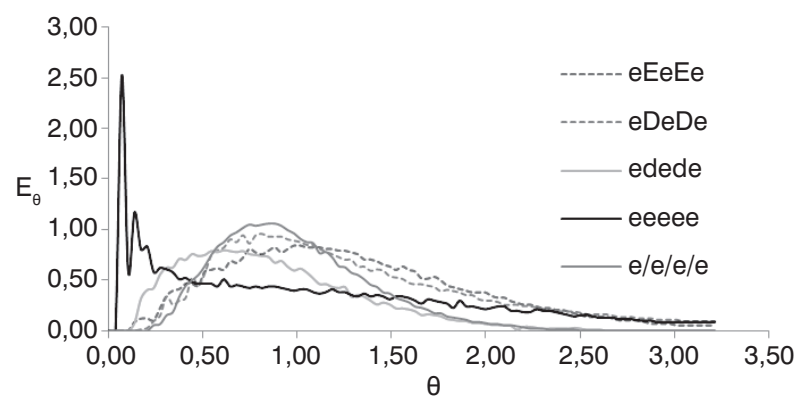

B

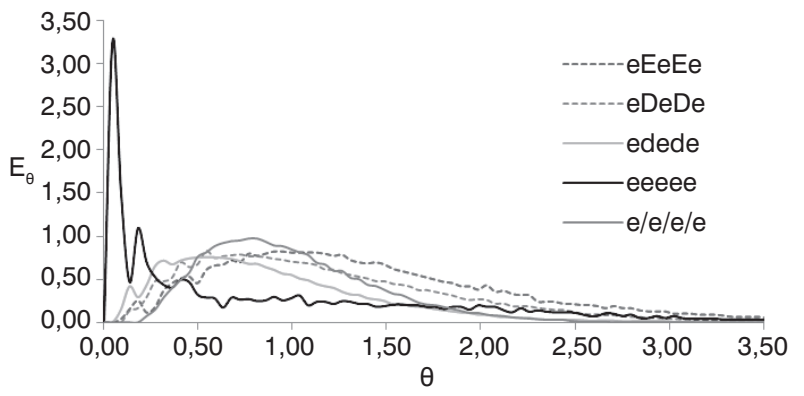

Figura 7 - Curvas DTR para unidade de floculação com (A) quatro e (B) três câmaras com os agitadores desligados.

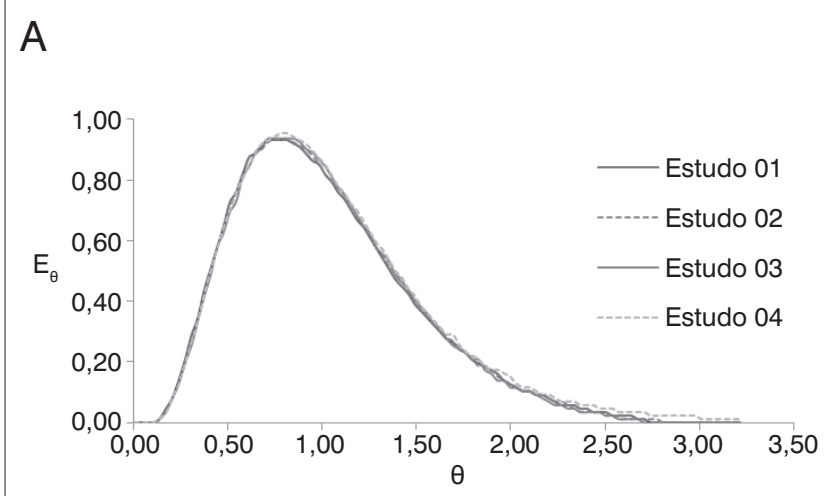

B

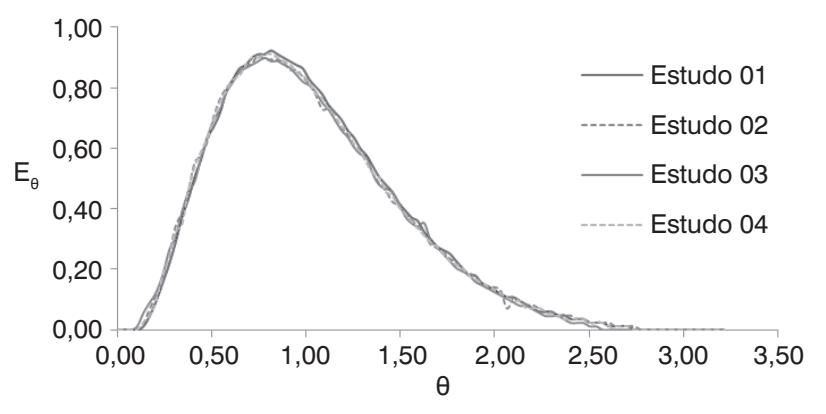

Figura 8 - Curvas DTR para unidade de floculação com quatro câmaras e configurações eDeDe (A) e eeeee (B). 
Todavia, os ensaios realizados para três câmaras de floculação exibiram nitidamente a relevância das configurações das passagens e, novamente, a configuração dotada de anteparos mostrou-se a mais adequada. Na Figura 9, apresentam-se as curvas DTR de duas das configurações de abertura para unidade de floculação de três câmaras.

Ao analisar de forma geral as curvas das DTR para floculador de quatro, três e duas câmaras, geradas a partir dos estudos supracitados e para as diferentes configurações de passagem, conclui-se que o sentido de rotação do agitador e a influência do gradiente de velocidade - constante ou variável - tornam-se mais relevantes ao passo que o número de câmaras diminui. Nas figuras 10, 11 e 12 são apresentadas as curvas DTR para as configurações de abertura com anteparo.

\section{Análise da aderência dos resultados experimentais ao modelo de tanques em série}

Na Tabela 1, apresenta-se a SEQ das curvas DTR experimentais obtidas para o floculador de quatro câmaras ( $\mathrm{T}=29,5 \mathrm{~min}$ ), para cada uma das cinco configurações de abertura avaliadas, em relação à curva do modelo de quatro tanques em série (Figura 3).

A análise dos valores da SEQ aponta que quanto menor esse valor, maior a aderência da curva experimental à curva do modelo. Neste contexto, a colocação dos anteparos resultou na melhor aderência ao modelo matemático para os quatro cenários avaliados. Esta tendência praticamente se manteve para as curvas DTR obtidas para unidade de floculação de três e duas câmaras, conforme evidenciam as Tabelas 2 e 3 .

Visando corroborar os valores da SEQ realizou-se a estatística descritiva apresentada na Tabela 4.

Os resultados expressos pela Tabela 4 tornam difícil afirmação peremptória em vista dos altos coeficientes de variação. Desta forma, os testes de hipóteses $t$ e F foram realizados para verificar se há diferenças significativas entre as médias das SEQ. No teste de significância, consideraram-se as raízes quadradas das SEQ, com o intuito de minimizar os erros, e os resultados dos ensaios com os agitadores

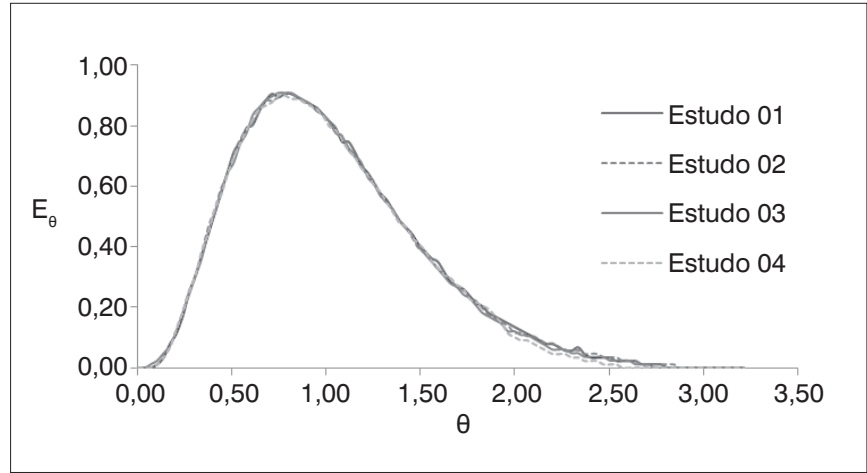

Figura 10 - Curvas DTR para unidade de floculação com quatro câmaras e configurações e/e/e/e/e.

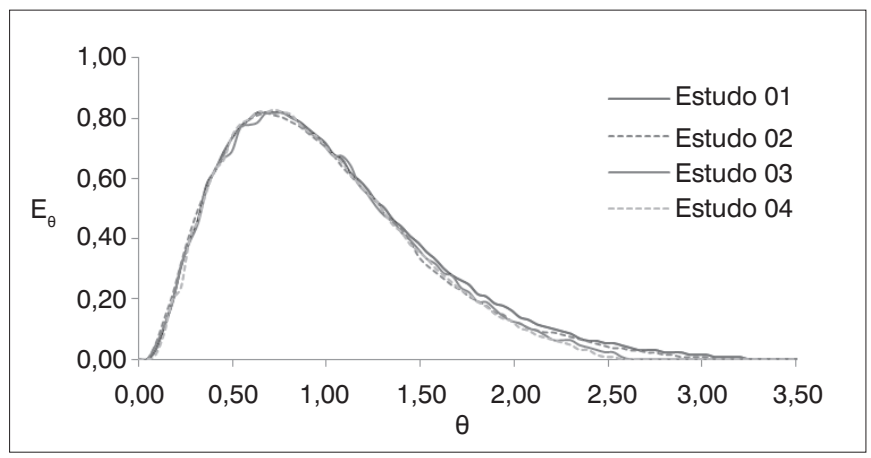

Figura 11 - Curvas DTR para unidade de floculação com três câmaras e configurações e/e/e/e.

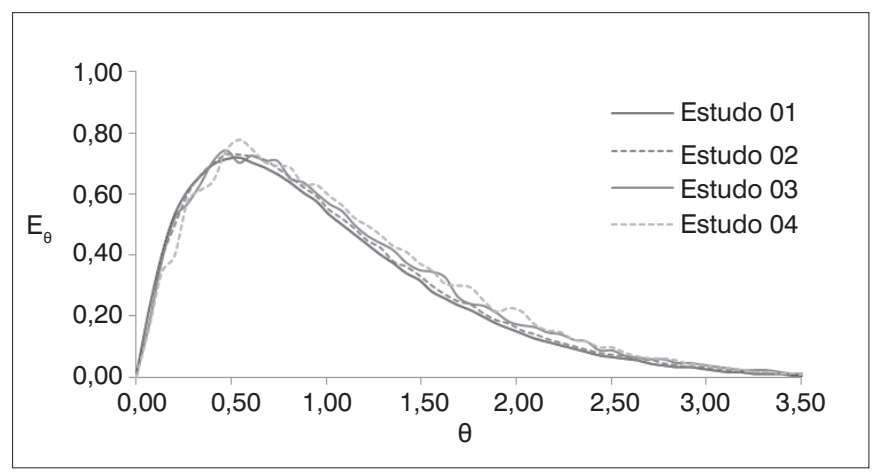

Figura 12 - Curvas DTR para unidade de floculação com duas câmaras e configurações e/e/e.

\section{A}

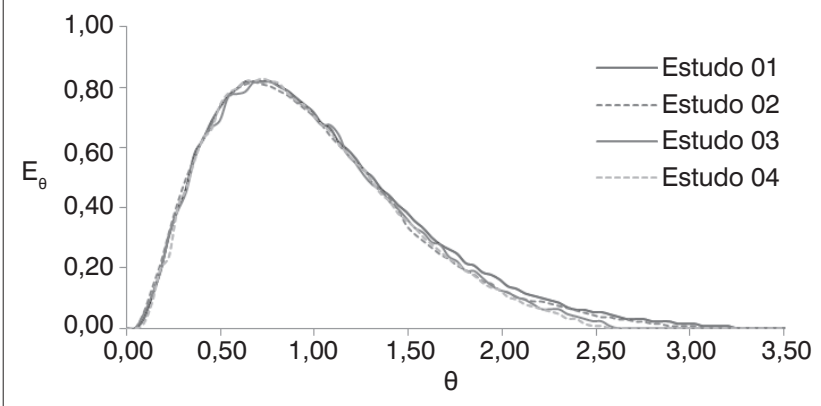

B

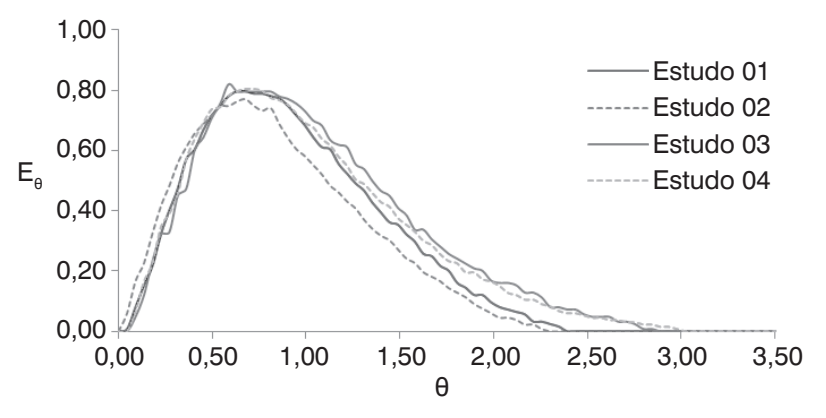

Figura 9 - Curvas DTR para unidade de floculação com três câmaras e configurações e/e/e/e (A) e eeee (B). 
desligados, culminando 15 ensaios para cada configuração (5 estudos e unidades de floculação com 2, 3 e 4 câmaras).

Por meio dos resultados dos testes de hipóteses te F, no nível de significância de 95\%, foi possível avaliar se havia diferenças significativas entre as médias das configurações, a partir das 10 comparações efetuadas $(\mathrm{N})$, conforme mostra a Tabela 5. Para cada teste ( $t$ e F), o termo $\mathrm{H}_{0}$ representa a hipótese de que as médias são iguais.

A diferença entre as médias não foi significativa com 95\% de confiança para quase todas as comparações, provavelmente devido aos altos valores dos desvios padrão. Na prática, ainda que a configuração eDeDe $(0,55)$ tenha se ajustado melhor ao modelo de tanques em série do que a configuração eEeEe $(0,85)$, os testes indicaram que esta diferença pode ser atribuída ao acaso, ou seja, a repetição dos ensaios provavelmente não levaria aos mesmos resultados.

Conclui-se a partir da análise da Tabela 5 que a configuração edede $(0,55)$ e e/e/e/e/e $(0,37)$ ajustaram-se melhor que a configuração eEeEe $(0,85)$ ao modelo de tanques em série. Tal assertiva indica que nos floculadores de quatro, três e duas câmaras com estas configurações de passagem os efeitos de curtos-circuitos e a formação de zonas mortas são menos significativos.

\section{Conclusões e recomendações}

A partir dos modelos matemáticos avaliados, dos resultados experimentais e da análise estatística pode-se concluir que:

i) Os efeitos sobre a curva DTR, provocados pela variação do sentido da rotação do agitador e do gradiente de velocidade, tornam-se mais pronunciados à medida que se reduz o número de câmaras. Para floculador de quatro câmaras, de emprego mais extensivo nas estações de grande porte, praticamente não se verificou influência destes parâmetros;

ii) Com relação à configuração das passagens entre as câmaras, os resultados mostraram que as curvas DTR assemelharam-se na presença da agitação. Apenas nos ensaios com os agitadores desligados, a configuração das passagens assumiu maior relevância;
Tabela 1 - Soma dos erros quadráticos para floculador de quatro câmaras.

\begin{tabular}{cccccc}
\multirow{2}{*}{ Estudo } & \multicolumn{5}{c}{ Configuração das passagens } \\
\cline { 2 - 6 } & eEeEe & eDeDe & edede & eeeee & e/e/e/e/e \\
\hline 01 & 0,28828 & 0,10861 & 0,05121 & 0,15745 & $\mathbf{0 , 0 9 0 5 2}$ \\
\hline 02 & 0,32127 & 0,13526 & 0,13117 & 0,07722 & $\mathbf{0 , 0 6 9 2 9}$ \\
\hline 03 & 0,32114 & 0,16760 & 0,15047 & 0,08509 & $\mathbf{0 , 0 7 3 2 9}$ \\
\hline 04 & 0,19297 & 0,20261 & 0,07425 & 0,09352 & $\mathbf{0 , 0 7 8 8 1}$ \\
\hline
\end{tabular}

Em negrito, os valores mínimos para cada estudo.

Tabela 2 - Soma dos erros quadráticos para floculador de três câmaras.

\begin{tabular}{cccccc}
\multirow{2}{*}{ Estudo } & \multicolumn{5}{c}{ Configuração das passagens } \\
\cline { 2 - 6 } & eEeE & eDeD & eded & eeee & e/e/e/e \\
\hline 01 & 0,66519 & 0,22391 & 0,06708 & 0,05991 & $\mathbf{0 , 0 5 7 0 5}$ \\
\hline 02 & 0,46300 & 0,24974 & 0,14758 & 0,27080 & $\mathbf{0 , 0 2 2 6 7}$ \\
\hline 03 & 0,28853 & 0,38423 & 0,07422 & 0,15258 & $\mathbf{0 , 0 5 8 2 1}$ \\
\hline 04 & 0,83440 & 0,47542 & 0,15120 & $\mathbf{0 , 0 3 5 2 2}$ & 0,07085 \\
\hline
\end{tabular}

Em negrito, os valores mínimos para cada estudo.

Tabela 3 - Soma dos erros quadráticos para floculador de duas câmaras.

\begin{tabular}{cccccc}
\multirow{2}{*}{ Estudo } & \multicolumn{5}{c}{ Configuração das passagens } \\
\cline { 2 - 6 } & eEe & eDe & ede & eee & e/e/e \\
\hline 01 & 0,24859 & 0,20586 & 0,01870 & 0,01239 & $\mathbf{0 , 0 0 5 5 6}$ \\
\hline 02 & 0,20297 & 0,14679 & 0,01471 & 0,03003 & $\mathbf{0 , 0 2 0 4 3}$ \\
\hline 03 & 0,33266 & 0,15552 & 0,05959 & $\mathbf{0 , 0 5 7 1 1}$ & 0,05907 \\
\hline 04 & 0,23881 & $\mathbf{0 , 0 8 7 8 0}$ & 0,09895 & 0,09895 & 0,14198 \\
\hline
\end{tabular}

Em negrito, os valores mínimos para cada estudo.

Tabela 4 - Estatística descritiva das somas dos erros quadráticos para as configurações de passagens avaliadas.

\begin{tabular}{|c|c|c|c|c|c|}
\hline \multirow{2}{*}{ Parâmetro estatístico } & \multicolumn{5}{|c|}{$\begin{array}{l}\text { Configuração das passagens para qua- } \\
\text { tro, três e duas câmaras de floculação* }\end{array}$} \\
\hline & A & B & C & D & E \\
\hline Média & 0,85 & 0,55 & 0,44 & 1,06 & 0,36 \\
\hline Desvio padrão (DP) & 0,57 & 0,27 & 0,39 & 1,61 & 0,24 \\
\hline Coeficiente de variação (\%) & 67 & 50 & 87 & 152 & 67 \\
\hline
\end{tabular}

*Configuração A - Representa as configurações de passagens eEeEe, eEeE e eEe. *Configuração B - Representa as configurações de passagens eDeDe, eDeD e eDe. *Configuração $\mathrm{C}$ - Representa as configurações de passagens edede, eded e ede.

*Configuração D - Representa as configurações de passagens eeeee, eeee e eee.

${ }^{*}$ Configuração D - Representa as configurações de passagens eeeee, eeee e eee.
${ }^{*}$ Configuração E - Representa as configurações de passagens e/e/e/e/e, e/e/e/e e e/e/e

Tabela 5 - Resultado do teste de significância para as diferenças entre as médias de soma dos erros quadráticos.

\begin{tabular}{|c|c|c|c|c|c|c|c|c|c|c|c|c|}
\hline \multirow{2}{*}{$\mathrm{N}$} & \multirow{2}{*}{$\begin{array}{c}\text { Configuração } \\
1\end{array}$} & \multirow{2}{*}{ Média } & \multirow{2}{*}{ DP } & \multirow{2}{*}{$\begin{array}{c}\text { Configuração } \\
2\end{array}$} & \multirow{2}{*}{ Média } & \multirow{2}{*}{$\mathrm{DP}$} & \multicolumn{3}{|c|}{ Teste $t$} & \multicolumn{3}{|c|}{ Teste F } \\
\hline & & & & & & & $t$ & tmax & Rejeita $\mathrm{H}_{0}$ & $\mathrm{~F}$ & Fmax & Rejeita $\mathrm{H}_{0}$ \\
\hline 1 & eEeEe & 0,85 & 0,57 & eDeDe & 0,55 & 0,28 & 1,86 & 2,05 & $\mathrm{~N}$ & 3,45 & 4,20 & $\mathrm{~N}$ \\
\hline 2 & eEeEe & 0,85 & 0,57 & edede & 0,45 & 0,39 & 2,25 & 2,05 & $\mathrm{~S}$ & 5,07 & 4,20 & $\mathrm{~S}$ \\
\hline 3 & eEeEe & 0,85 & 0,57 & eeeee & 1,06 & 1,62 & 0,47 & 2,05 & $\mathrm{~N}$ & 0,22 & 4,20 & $\mathrm{~N}$ \\
\hline 4 & eEeEe & 0,85 & 0,57 & $\mathrm{e} / \mathrm{e} / \mathrm{e} / \mathrm{e} / \mathrm{e}$ & 0,37 & 0,25 & 3,01 & 2,05 & $S$ & 9,06 & 4,20 & $S$ \\
\hline 5 & eDeDe & 0,55 & 0,28 & edede & 0,45 & 0,39 & 0,85 & 2,05 & $\mathrm{~N}$ & 0,72 & 4,20 & $\mathrm{~N}$ \\
\hline 6 & eDeDe & 0,55 & 0,28 & eeeee & 1,06 & 1,62 & 1,21 & 2,05 & $\mathrm{~N}$ & 1,46 & 4,20 & $\mathrm{~N}$ \\
\hline 7 & eDeDe & 0,55 & 0,28 & e/e/e/e/e & 0,37 & 0,25 & 2,01 & 2,05 & $\mathrm{~N}$ & 4,03 & 4,20 & $\mathrm{~N}$ \\
\hline 8 & edede & 0,45 & 0,39 & eeeee & 1,06 & 1,62 & 1,43 & 2,05 & $\mathrm{~N}$ & 2,04 & 4,20 & $\mathrm{~N}$ \\
\hline 9 & edede & 0,45 & 0,39 & e/e/e/e/e & 0,37 & 0,25 & 0,69 & 2,05 & $\mathrm{~N}$ & 0,47 & 4,20 & $\mathrm{~N}$ \\
\hline 10 & eeeee & 1,06 & 1,62 & $\mathrm{e} / \mathrm{e} / \mathrm{e} / \mathrm{e} / \mathrm{e}$ & 0,37 & 0,25 & 1,65 & 2,05 & $\mathrm{~N}$ & 2,71 & 4,20 & $\mathrm{~N}$ \\
\hline
\end{tabular}

DP: desvio padrão; t: diferença comparativa entre as duas configurações testadas pelo teste $t$ de Student; tmax: valor crítico para o teste $t$; Rejeita $\mathrm{H}_{0}$ : não há diferença significativa entre as configurações?; $\mathrm{F}$ : diferença comparativa entre as duas configurações testadas pelo teste $\mathrm{F}$ de Fischer; Fmax: valor crítico para o teste $\mathrm{F}$; Rejeita $\mathrm{H}_{0}$ : não há diferença significativa entre as configurações?; N: não; S: sim. 
iii) A instalação do anteparo à frente das passagens diretas mostrou-se alternativa eficiente, principalmente na ausência da agitação promovida pelos agitadores. Com a colocação dos anteparos as curvas desta configuração tornaram-se semelhantes às das configurações mais recomendadas pelas práticas de projeto de estações de tratamento de água. Esta constatação pode fornecer importante ferramenta para minimizar o curto-circuito em floculadores em escala real dotados desta configuração de passagens;

iv) As configurações edede e e/e/e/e/e ajustaram-se melhor - no nível de significância de 95\% - ao modelo tanques em série do que a configuração eEeEe, para floculadores de quatro, três e duas câmaras, indicando que os efeitos de curtos-circuitos e de formação de zonas mortas são menos significativos.

\section{Agradecimentos}

À Coordenação de Aperfeiçoamento de Pessoal de Nível Superior (CAPES) - Programa Procad (218/2007) - e à Fundação de Amparo à Pesquisa (FAPEMIG) - Programa Pesquisador Mineiro (Processo TEC APQ 4754-6).

\section{Referências}

ABNT. (1992) Projeto de estação de tratamento de água para abastecimento público, NBR 12.216. Rio de Janeiro: ABNT. 18 p.

AMIRTHARAJAH, A; CLARK, M.M.; TRUSSELL, R.R.; AMERICAN WATER WORKS ASSOCIATION. (1991) Mixing in coagulation and flocculation. Denver: AWWA Research Foundation. 426 p.

BRATBY, J.R. (1981) Interpreting laboratory results for the design of rapid mixing flocculation systems. Journal of American Water Works Association, v. 73, n. 6, p. 318-25.

CAMP, T.R. (1955) Flocculation and flocculation basins. ASCE Transactions, v. 120, p.1-16.

CAMPOS, L.C. (1992) Influência das características geométricas do agitador de paletas giratórias paralelas ao eixo vertical na potência introduzida na água. Dissertação (Mestrado). Escola de Engenharia de São Carlos da Universidade de São Paulo, São Carlos.

DI BERNARDO, L.; DANTAS, A.D. (2005) Métodos e técnicas de tratamento de água. 2 ed. São Carlos: Rima. v. 2, 784 p.
HUDSON JR., H.E. (1975) Residence times in pretreatment. Journal of American Water Works Association, v. 67, n. 1, p.45-52.

INSTITUTO BRASILEIRO DE GEOGRAFIA E ESTATÍSTICA (IBGE). Pesquisa Nacional de Saneamento Básico - 2008. Disponível em: <http://www.ibge.gov.br>. Acesso em: 12 mar. 2011.

LEVENSPIEL, O. (2000) Engenharia das reações químicas: cálculo de reatores. São Paulo: Edgard Blücher. 344 p.

LIBÂNIO, M. (2010) Fundamentos de qualidade e tratamento de água. 3 ed. Campinas: Átomo. $494 \mathrm{p}$.

REBHUN, M.; ARGAMAN, Y. (1965) Evaluation of hydraulic efficiency of sedimentations basins. Journal of Sanitary Engineering - ASCE, v. 91, n. 5, p.37-45.

STEEL, R.G.D.; TORRIE, J.H. (1960) Principles and procedures of statistics. New York: McGraw-Hil. 481 p.

TEEFY, S. (1996) Tracer studies in water treatment facilities: a protocol and case studies. Denver: AWWA Research Foundation. $152 \mathrm{p}$ 